\title{
Participatory Communication and Perceptions amongst Staff Members at a Tertiary Education Institution
}

\author{
J Jooste \\ North-West University, Vaal Triangle Campus, \\ P.O Box 1174, Vanderbijlpark, 1900, South Africa \\ Jani.jooste@nwu.ac.za \\ C van der Vyver \\ North-West University, Vaal Triangle Campus, \\ P.O. Box 1174, Vanderbijlpark, 1900, South Africa \\ Charles.vandervyver@nwu.ac.za
}

\section{Doi:10.5901/mjss.2014.v5n7p631}

\begin{abstract}
Within the field of development, participation has become the normative approach in the past two decades. For development projects to be sustainable, the communication must be participatory in nature. Against this background, this research investigated the extent to which communication between personnel of a specific tertiary education institution is effective and participatory. The population for this study is the 100 staff members of the Faculty of Economic Sciences and Information Technology at the Vaal Triangle Campus of the North-West University in South Africa. The entire population was used in the study to ensure that all perspectives were included, whether academic, management or support services. A questionnaire was composed and handed out to all personnel to determine their perceptions regarding communication within and about the Faculty, after which the collected data was analysed quantitatively. The research findings reveal that within the larger paradigm of heteroglossia there is room for improvement. This study pointed out the various areas for improvement and offered theoretically grounded recommendations. The institution should develop a well researched marketing and communication plan that focuses on the different mediums that are used to communicate with personnel as well as the messages that are being communicated. Future research into development communication for social change and perceptions amongst staff members at tertiary education institutions should focus on the development of interesting messages to address the dynamic target group of academics, and also on continuous development of different communication and information campaigns within tertiary education institutions, to ensure that communication campaigns stay new and fresh.
\end{abstract}

Keywords: participatory communication; communication management; participatory model; communication for social change; stakeholder; stakeholder management

\section{Introduction}

Within the field of development, participation has become the normative approach in the past two decades. For development projects to be sustainable, the communication must be participatory in nature.

For development projects to be sustainable and to actually contribute to the development of communities, communication has to be based on the participatory approach of development communication. Dialogue, empowerment that leads to independence and cultural identity are some of the most important principles of the participatory approach. The importance of communication aimed at development first became apparent during the modernisation paradigm. Modernisation is considered an evolutionary shift from a traditional view to a modern society. Development is seen as synonymous with westernization, industrialization and economic growth. Against this background, the following research question was investigated: to what extent is the communication between personnel of the Faculty of Economic Sciences and IT effective and participatory?

The researcher used a quantitative research method in order to collect the data. A literature study was conducted to explore the premises of the nature of the participatory approach in development communication for social change. A questionnaire was composed and handed out to all personnel member within the Faculty of Economic Sciences and IT determine their perceptions regarding communication within and about the Faculty.

The research findings reveal that within the larger paradigm of heteroglossia there is room for improvement. This 
study pointed out the various areas for improvement and offered theoretically grounded recommendations.

\section{Participatory Communication as the Norm}

During the 1950s and 1960s the modernisation paradigm was the dominant paradigm within the discipline of development communication. Modernisation is the standardised, evolutionary shift from a traditional view to a modern view of a society and can be seen as synonymous with the term westernisation, industrialisation and economic growth (Servaes, 1995:36; Agunga, 1999:145). The supposition during this time was that developing countries had to diverge from their old way of life and adopt the lifestyles, ideas, technologies and innovations of developed countries (Melkote, 1991:60; Crabtree, 1998:183; Mefalopulos \& Genna, 2004:24; Chitnis, 2005b:232). This paradigm developed against the backdrop of a school of thought which saw modernisation, and by implication economic growth, industrialisation and westernisation, as a necessary means to bring an end to poverty. The main goal behind modernisation was to improve economic and social conditions in poor areas, as well as to establish modern institutions, values and practices. Developing states had to simulate the industrialised model of developed states (Agunga, 1999:40,145; Nules, 2003:71).

Since the modernisation paradigm held that development is a linear process, communication was also regarded as one-directional. The receiver was branded as a passive being that the media could manipulate. The strongest criticism that can be levelled against the modernisation paradigm is its view of communication as a one-way process. The modernisation paradigm is also criticised for ignoring the importance of cultural and political development, as well as its lack of addressing actual needs (Servaes, 1995:41; Crabtree, 1998:183; Melkote \& Steeves, 2001:218; Yoon, 2004). Taking the criticism against modernisation into account, it can be assumed that one-way communication during the modernisation period did not lead to sustainable development (Melkote, 1991:57, 67; Servaes, 1995:41; Malan, 1998:14; Moemeka, 1999:5; Servaes, 2000:86; Moemeka, 2002:8; Mefalopulos \& Genna, 2004:27; Servaes \& Malikhao, 2008:160). In reaction to criticism on the modernisation paradigm, several other approaches to communication took shape, all aimed at development and the facilitation of social change.

The hunt for a theory that can explain underdevelopment resulted in the development of the dependence approach (Haddad \& Spivey, 1992:3; Melkote \& Steeves, 2001:22; Yoon, 2004:2-3). This approach can briefly be described as the aspiration of developing countries to act independently. Developing countries wanted to break away from developed countries as they felt that these countries were forcing them to adopt their modern lifestyle. The problem with this strive towards independence was that these countries were simply economically too weak to make an autonomous existence possible. They did not take their internal shortcomings into account. Although the dependence approach tried to address the causes of underdevelopment, it did not yield any methods which could be used to tackle underdevelopment (Servaes, 1995:40). The need arose for a new understanding of development that considers cultural identity, multidimensionality and the need for greater development. This is where the multiple approaches (1970s-1980s) first started forming, with its emphasis on satisfying needs (Servaes, 1995:41). This approach was the first step towards the participatory approach.

The participatory approach can be seen as an approach that grants all parties an equal opportunity to share their knowledge, as opposed to one-directional communication aimed at persuading people. Communities are encouraged to participate freely in conversations and to contribute ideas to projects that are planned in conjunction with them. Participation emphasises that all stakeholders should be consulted and considered during projects in order to improve living standards, ranging from the creation of the programme to its implementation, as well as in other decision-making processes (Melkote, 1991:270; Jennings, 2000:35; Chitnis, 2005a:27). For development projects to be sustainable and truly contribute to the development of communities, communication must be based on the premise of the participatory approach to development communication (Servaes, 1995:56; Malan, 1998:52; Agunga, 1999; Melkote \& Steeves, 2001:47; Moemeka, 1999:7). Participatory communication for sustainable development is concerned with empowerment, which leads to self-sufficiency, dialogue and cultural identity. These are basic indicators of the participatory approach (Nair \& White, 1993:54; Rahim, 1994:6,120; Jacobson \& Kolluri, 1999:268; Melkote \& Steeves, 2001:252).

Briefly looking at these indicators, dialogue can be described as a two-way process of mutual understanding. Without this process, development projects cannot address the true needs of communities. Dialogue can also be regarded as the ideal conversation situation that takes place between equal participants, providing the opportunity to discuss and solve the needs and problems of the community (Rahim, 1994:20; Servaes, 1995:39; Bakke \& Subedi, 2008:78). Without effective and efficient dialogue, the objectives of the development project cannot be achieved (Melfalopulos, 2005: 254). Chitnis (2005a:239) refers to empowerment as the ability to control decision-making in matters and situations that influence our lives. People's right to be involved and to be heard is at the core of participatory development, and is achieved by means of empowerment. Individuals and communities are empowered by gaining knowledge about specific matters, communicating about issues that are of general importance, making their own 
decisions and negotiating power relationships. Through empowerment, participants can thus satisfy their basic needs, cultivate self-esteem, pursue choices that will realise their human potential and acquire collective thinking patterns (Rahim, 1994:118; Servaes, 1995:43; Fourie \& Kloppers, 2009:93).

However, within the development context communication often takes place between members of different cultural groups. Mefalopulos (2005:251) is of the opinion that all stakeholders in a project should have the same idea and understanding of problems within the project. By considering everyone's cultural background, beliefs and traditions, the best possible solution with the most significant common denominator can be negotiated.

\section{Assumptions towards the participatory model: empowerment and dialogue}

\subsection{Empowerment}

Over the past decade, much emphasis has been placed on empowerment within the development context as a means of addressing unchanged social problems (Langenhoven, 2001:123).

Empowerment can be seen as the process through which power is divided between different individuals or groups so that all parties have more or less the same power. During participation, communities share power and knowledge on a social, economic and political level. The flow of information and communication are key elements to establishing empowerment. Within the development context, this implies that power is delegated so that each individual in the community has some form of power that they can use to help themselves, at the very least. Empowerment requires of individuals to take ownership of the power they receive and to improve their intellectual abilities and individual potential (Langenhoven, 2001:123; Agunga, 1996:184; Waisbord, 2001:3).

Any individual or group has the right and freedom to express their opinion about a situation in which they are involved. Empowerment is when people transform of their own free will and build self-confidence in order to achieve independence. In this way individuals can take control of their lives and achieve their full potential, in the process improving their standard of living (Agunga, 1996:184; Waisbord, 2001:3; Langenhoven, 2001:124; Schultz, 2003:203).

The central concept of Freire's theory of emancipation (liberation of the oppressed) is conscientisation(consciousmaking). This refers to the process through which man becomes conscious of the socio-cultural reality that shapes his life and that it is within his power to transform that reality into something better. Conscientisation is seen as the creation of awareness through the transfer of knowledge (Chitnis, 2005a:83; Servaes, 1995:45-46).

Conscientisation implies action and reflection on the situation; people need to reflect on their own lives and the situation they are in. The word action implies the process of becoming aware, and reflection is taking words and sentences and understanding them. It considers what the term, word or sentence means to you and how it affects and can change your life. According to the Baktinian perspectives on communication one can only be actively engaged when one absorbs information - dialogue is critical to becoming more conscious. There is no true learning without acting on situations, and no meaningful acting without reflection on the situation (Roberts, 2010:6). Conscientisation demands that we strive to extend our current understanding of a situation, and that we are willing to question current ways and seek better knowledge of ourselves and the world we live in. It is the process that allows individuals to actively participate in the investigation of their environment and to question the structures that lead to oppression. Empowerment, amongst other things, enables communities to generate an income and overcome oppression (Mies, 1973:1767; Roberts, 2010:8).

Empowerment is not purely centred on economic pursuits, and focuses on improving the quality of life of communities by meeting their material and non-material needs. Through empowerment, individuals are taught particular qualities that enable them to adopt processes of social change as opposed to simply adopting the processes and ideas of Western experts (Malan, 1998:52; Waisbord, 2001:17).

Empowerment fosters independence, since individuals learn how to solve their own problems and function independently from figures of authority. Independence teaches communities to stand up for what they believe in, to take full control of their environment and make decisions regarding situations that influence their lives. Lastly, independence leads to the start of projects, which in turn ensures sustainable progress for the community (Mefalopulos, 2005:256; Cadiz, 2005:156; Chitnis, 2005b:293).

Empowerment comprises two dimensions: the personal dimension, which deals with individuals' self-assurance and self-respect and enables them take on new tasks and become actively involved in these activities; and the group dimension, which deals with empowering the community by giving individuals access to information and giving them the opportunity to participate in decision-making.

Independence involves not only being able to care for your family in an independent manner, but also being able to act independently in work situations. The decisions made within an organisation can influence progress. Including the 
local community in the decision-making and planning processes will lead to them making their own decisions and contributing to their own progress. This ensures that everyone enjoys the benefits of the project. In addition to this, it also draws support for projects and leads to people taking the initiative to launch their own projects and empower the community.

Through empowerment, participants can satisfy their basic needs, foster self-respect, choose to realise their human potential and acquire collective thinking habits.

Participatory communication is the foundation of empowerment. The aim is to empower individuals by means of communication, which encourages them to identify needs, ideas and solutions and to realise these solutions. According to Cadiz (2005:150-157), communication for empowerment deals more with listening and facilitating dialogue than speaking. The facilitator has to encourage two-way communication between the relevant parties. Information should not simply be given to interest groups through one-way communication. Individuals should learn together rather than be taught.

One can say that communication that takes place from the bottom up increases decision makers' awareness of a particular problem, and trains and empowers the community to act independently by identifying and solving their own problems (Servaes, 2000:191).

\subsection{Dialogue}

The preceding section has argued that communication is central to the process of empowerment. This section emphasises the role that dialogue, as a form of communication, plays in empowerment (Mefalopulos, 2005:251).

Communication is a prominent human need. Each individual has the need to send and receive messages, and to express his or her thoughts (Kamboura, 2008:2). Communication can be described as the symbolic, interpretative, transactional, and conceptual process of sharing a specific message and transferring knowledge or information. It is a process of negotiation during which people from different cultures come into contact and where the meaning of the message is clearly understandable to all of those involved. It is the process of talking and asking questions in order to make new discoveries and understand different worlds (O'Sullivan et al., 1994:50; Waisbord, 2001:18; Lustig \& Koester, 2005:9-10, Roberts, 2010:6).

Humans have the capacity to formulate thoughts and to convert these thoughts into symbols. These symbols are then expressed using speech and non-verbal communication. However, communication is more than words, sentences and syntax; it involves all kinds of non-verbal nuances that include paralanguage, kinesics, proxemis, facial expressions and personal appearances. People are bundles of communication signals, both intentional and unintentional (Roberts, 2010:6)

Communication is more than the mere transmission of information, but complete and effective dialogue is the product of multiperson interaction. No communication relationship can be built without dialogue (O'Sullivan et al., 1994:94; Waisbord, 2001:18; Roberts, 2010:9). No community can exist without dialogue between its members. It is important that there is interaction between the members of a community and that they share dialogue, experiences and opinions with one another (Rahim, 1994:120; O' Sullivan et al., 1994:49). Face-to-face communication and interaction provides people with the opportunity to express new ideas. Rahim (1994:20) argues that there can be no familiarity without dialogic communication. This implies that there has to be mutual communication with a view to bringing about a positive change of circumstances between all of the involved parties in order for development to take place. Without effective and efficient dialogue, the objectives of the development project cannot be achieved (Mefalopulos, 2005:254).

Kamboura (2008:3) argues that effective communication has a positive influence on the community and the operations of the organisation. When people are in a position to express their frustrations and talk about their problems, plans can be formulated collectively to solve these problems. Effective communication influences productivity and performance and leads to sustainable development (Servaes, 1995; Melkote \& Steeves, 2001:252).

According to Shapo (2000) and Maki et al (2009), the following obstacles to effective communication should be considered:

- Climate control: There must be an open climate that encourages people to communicate. They should have the opportunity and medium with which to communicate. All members must have an equal right to communicate.

- Status: The position that an individual holds in a group may influence communication. People on lower levels are not always willing to communicate with managers. Differences in status can impede communication and should be duly considered. 
- Communication overload: When there is an overload of information, mistakes can be made, priorities misplaced, and important tasks omitted. Work cannot then be performed properly and delegation takes place. This poses a big risk for organisations.

Communities need effective communication in order to learn. Educational dialogue has a clear purpose and focuses on addressing problems, rather than merely giving the answers to these problems. Active participation and dialogue create the opportunity for individuals to identify their needs by making use of indigenous knowledge, among other things (Taylor, 1993:56-57; Rahim, 1994:118, Roberts, 2007:513). Communities become a part of their own development and problem solving process.

\subsection{Heteroglossia}

Heteroglossia can be defined as the diversity of voices. The powers of these voices are in the centriphil (coexistence) and in the centrifugal (conflicting) force between types of speech. The centriphil force is the binding of words that have the same point of view, this makes communication possible. Centrifugal forces are pull-away forces where creation and expression of new ideas takes place.

Each person creates their own glossary complete with their own connotation to words and expressions, unique to that individual. Individual glossaries will differ from one another. However, where those glossaries match with a reasonable degree of accuracy the meaning can be exchanged and dialogue can occur.

This article rests upon the premise that the Faculty being studied functions on the same basis as other development programs. As stated above this development programmes should adhere to the basic indicators of participatory communication in order to be sustainable and contribute to the development of personnel and students. All personnel within the Faculty should therefore communicate according to the guidelines of the participatory approach.

\section{Research methods}

\subsection{Participants}

The population for this study is the 100 staff members of the Faculty of Economic Sciences and Information Technology at the Vaal Triangle Campus of the North-West University in South Africa. The entire population was used in the study to ensure that all perspectives were included, whether academic, management or support services. The study was limited to the one faculty due to financial and time constraints.

\subsection{Questionnaire composition}

A quantitative approach was followed using a questionnaire as the survey instrument. Questions were formulated with the objective of identifying the perceptions of staff in an academic environment toward communication.

\subsubsection{Demographic data}

Demographics of the participants were asked to establish the composition of the group in terms of age, race, gender, home language, years of service, etc. Some of the questions asked included

To what racial group do you belong?

Your native (home) language?

Years of service at the university?

\subsubsection{Attitude toward communication}

A few questions were asked regarding the attitude of the participants towards communication. Some of the questions asked included

I believe communication within the faculty is important.

I believe that sufficient communication, within the faculty, can have a positive influence on my academic work life.

To assess the attitudes the 5-point Lickert Scale was used. It formed the basis for not only this section, but for the 
majority of questions throughout the questionnaire.

$\square$ Strongly agree $\quad \square$ Agree $\square$ Neutral/No idea $\quad \square$ Disagree

\subsubsection{Culture}

Two questions were asked to determine the participants' view regarding the role of culture in faculty communication. These questions were

I think that communication in the faculty is representative of all cultural groups.

If a communique lends itself towards different cultural perspectives, would you like to see all these perspectives covered?

\subsubsection{Empowerment}

In this section questions were asked to determine whether participants feel empowered by current modes of communication. Some of the questions that were asked include

I feel that communication in the faculty, presents me with possibilities for empowerment.

The current methods of communication motivate me to be part of faculty initiatives.

\subsubsection{Communication frequency and content}

The purpose of the three questions in this section was to get a sense of how often staff members would like to receive communication, and what they would like to have communicated. The questions were

I would like communication via (tick as many as appropriate).

How regularly would you like to receive communication?

I want to read about (tick as many as appropriate).

\subsubsection{Communication channels}

This section focused on determining to what the degree current communication channels are successful or not. It also gave participants the opportunity to indicate how they would like to get more involved in faculty communication, if they desire to. Questions were mainly yes or no questions, and asked for a motivation if the answer was no. Some of the questions asked include

I visited the faculty Facebook page in the last month.

How do you see your role in communication (tick as many as appropriate)?

Lastly in an open ended question, the participants were asked to write any other remarks or views they might have on communication within the faculty that was not addressed in the questionnaire.

The pilot questionnaire was tested by a group of communication lecturers in the School of Languages. Some minor changes were suggested and made, after which it was distributed for completion to the members of the faculty.

\section{Findings}

\subsection{Demographics}

A response rate of $67 \%$ was achieved in the study out of the population of 100 . The 67 responses were made up of 60 from academic staff members, 5 from support services, and 2 from management. This is very similar to the staff profile in the population. The participants were made up of 41 females, and 26 males, the age profile of whom can be seen in figure 1. 


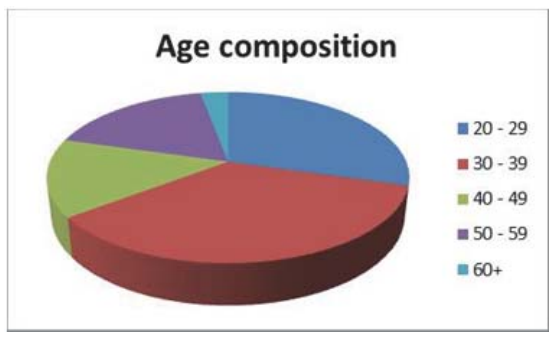

Figure 1: Age composition of participants

Figure 2 illustrates the racial composition of the participants, which is also very similar to the profile found in the population. When asked whether they have ever had a communication subject as part of one of their qualifications, 25 indicated yes, which it is felt will influence their perception regarding communication.

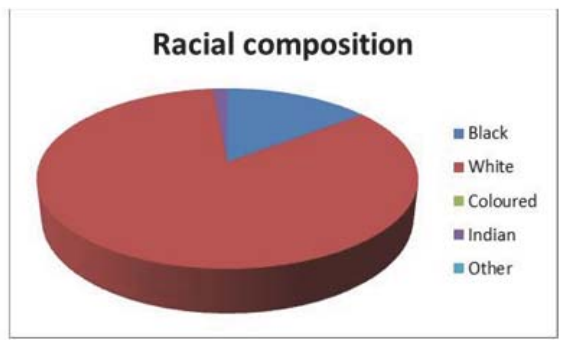

Figure 2: Racial composition of participants

Eight different home languages are spoken by the participants, seven of South Africa's official languages, and one native to Belgium, indicating a truly diverse working environment and group of colleagues. Figure 3 indicates that overall the staff are fairly inexperienced, which might increase their need for communication as they consider it one of their main sources of information.

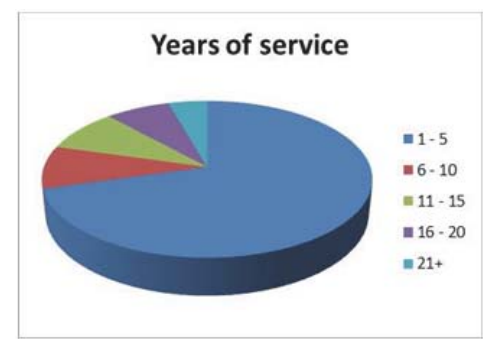

Figure 3: Years of service of the participants

\subsection{Communication mediums}

Various communication channels are currently in use in the faculty. The research indicated the highest preference for electronic communications. Figure 4 highlights the preferences. Faculty teas are informal gatherings where management provides feedback on newsworthy events happening within the faculty, after which everyone present has the opportunity to socialise. The channel highlighted under other was text messaging, which might be effective if time is critical, but it will greatly limit the amount of content. Newsletters are currently distributed electronically, and in printed format, but based on the findings the majority of the preferences can be satisfied by focusing on the electronic newsletter. 


\section{Preferred communication} channels

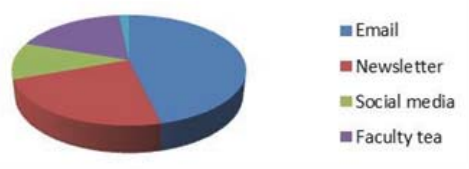

Figure 4: Preferred communication channels within the faculty

Figure 5 indicates the required frequency of communication of the participants. Currently communication takes place monthly, with exceptions for more frequently but never for less frequently. Current communication takes place over various channels, but if a shift was to be made towards more email communication (as indicated in figure 4), it can be achievable to increase the frequency of the communique. It is also important to indicate that all the respondents agreed that frequent and effective communication is important. None of the respondents indicated that they did not think communication to be important.

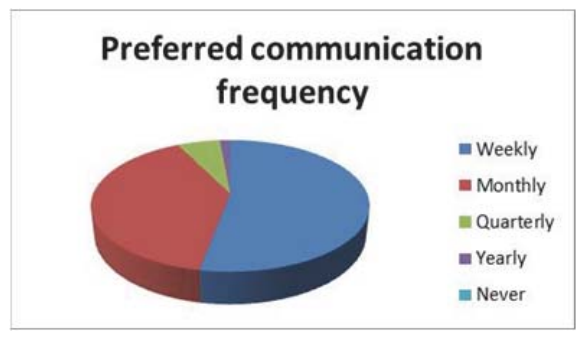

Figure 5: Preferred communication frequency within the faculty

Although 8 different home languages were indicated in the demographic section of the questionnaire, only three were indicated as preferred faculty communication languages (see figure 6). The overwhelming majority indicated a preference for Afrikaans and English, the languages in which current communication takes place, therefore current methods are satisfying language preferences.

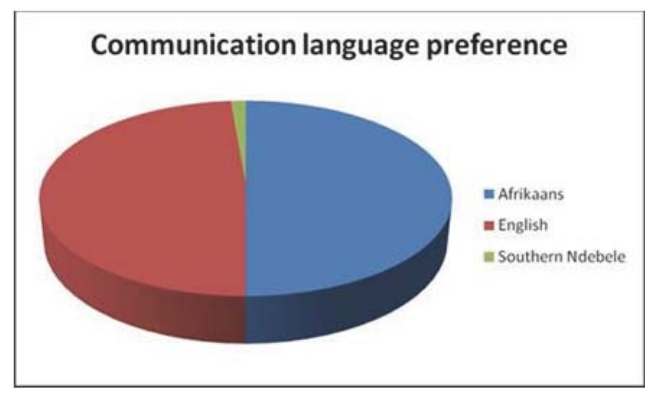

Figure 6: Communication language preference within the faculty

Figure 6 indicated that the main communication languages are Afrikaans and English. A few respondents indicated that their communication preference is Southern Ndebele.

The North-West University as a multi language policy, the three languages in this policy is Afrikaans, English and Setswana. According to this language policy news should be communicated in two of the three NWU languages.

This figure indicated that by communicating in both Afrikaans and English the majority of the respondents will understand and interpret the message as it was intended. 


\subsubsection{Mass media}

The Faculty of Economic Sciences and IT has their own quarterly newsletter, namely eBits. Figure 7 indicates how respondents read this email distributed newsletter. Majority indicated that they only read parts of the eBits if they read it at all.

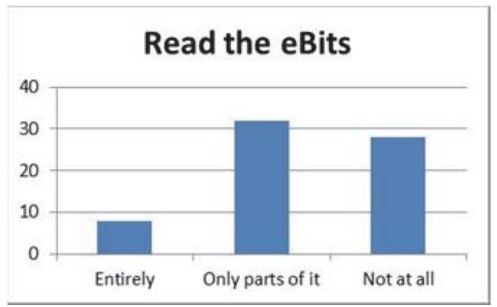

Figure 7: Feedback on eBits readership

The Faculty should therefore re-examine this medium of communication, as it is currently not a successful medium.

\subsubsection{Social media and online content}

As shown in figure 8, there are currently three types of online communication channels in use. As only about $11 \%$ of participants indicated that they use Twitter, it is not an efficient channel and not worth the effort of maintaining it. With about 40\% indicating that they use the Facebook page, it is worthwhile maintaining it, and the most effective social media channel currently in use. The faculty website was however the most efficient channel, with about $50 \%$ of participants indicating that they use it on a regular basis.

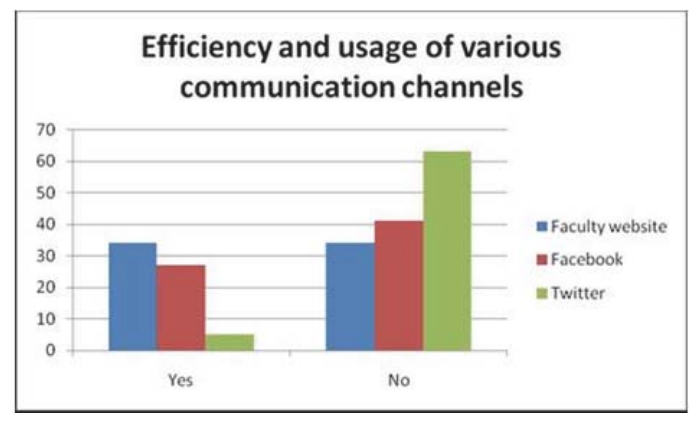

Figure 8: Efficiency and usage of various communication channels

Dialogue can take place through using different mediums. A communication medium is simply how a person sends the message to the receiver. It is critical to realise that the communication medium used to communicate a message is just as important as the message itself. If a wrong medium is chosen for a spesific target audience the message may never get through to the receiver or may be misunderstood. An individual should therefore use a medium appropriate to the group he/she is communicating with. Waisbord (2005:81) is of the opinion that media such as drama, community radio and choirs can make a valuable contribution to dialogue within small groups. Messages must be formed in such a way that they appeal to the different communities they are aimed at (Anon, 2013a).

eFundi is the current online based Learning Management System employed by the North-West University. It has the ability to host course and project sites, and is not only an effective communication channel, but also a very useful data repository. It was thought previously that a faculty eFundi page will not be an effective communication channel, but based on the responses received, it will definitely be worthwhile setting up and maintaining such a site (see figure 9). The majority of staff members access eFundi a couple of times a week to communicate with their students, and this might be the reason why such a site might prove to be very effective. 


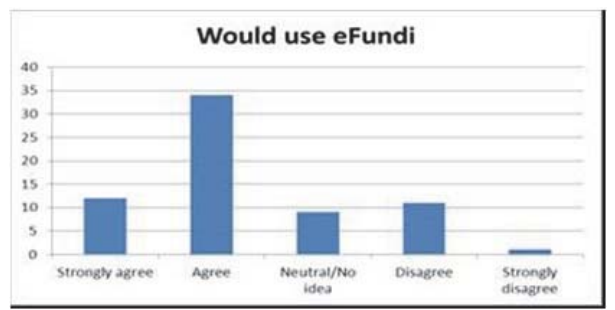

Figure 9: Usage of eFundi

eFundi is a portal used by lecturers to effectively communicate with students and upload documents to them to support their studies. By creating a tab for lecturers they can view the news and announcements daily if they enter the site to communicate with their students. As indicated in figure 9 the majority of respondents agreed that this was a good way to communicate with Faculty personnel.

\subsection{Type of news to be communicated}

Including relevant content in communication is vital to ensure the efficiency of communique.

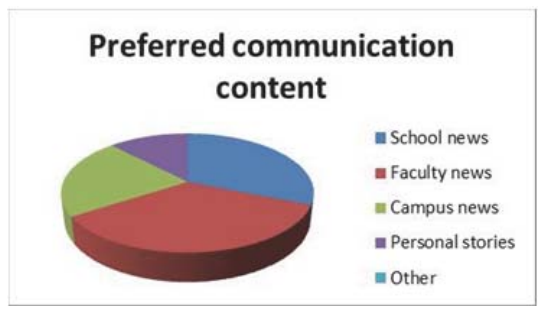

Figure 10: Preferred faculty communication content

Figure 10 indicates the four types of content covered in current communication. Other was included to research the possibility of expanding current content, but no other suggestions were made. As can be expected there was a high preference for faculty news, with personal stories receiving the lowest interest.

\subsubsection{Empowerment}

Dialogue can be considered as the ideal interview situation between equal participants, where the needs and problems of the project can be discussed and resolved (O' Sullivan et al., 1994:50; Waisbord, 2001:18; Lustig \& Koester, 2005:9-10, Roberts, 2010:8).

Section 3.2 describes the great influence effective communication has on a project. It is crucial for stakeholders to engage in communication with each other and to understand the messages exchanged to reach the goal. By examining the dialogue between stakeholders, the researcher can determine if there is trust between the stakeholders and if they feel free to communicate with each other. Different communication mediums should be utilized to ensure all the stakeholders have the opportunity to voice their ideas and concerns.

Dialogue is also the foundation of empowerment (see paragraph 2.3.2). Communication within the participatory paradigm states that individuals should communicate with each other and participate in the projects. Development projects should not be forced onto individuals and these projects should address the basic needs of individuals (Servaes \& Malikhao, 2008:163, 169; Matunhu, 2011:66; Nyamnjoh, 2005). There must therefore be dialogue between different stakeholder to ensure that participation and empowerment take place within the development project.

As discussed in sections 3.1, empowerment is plays a very important role participatory communication. Empowerment means to equip people with knowledge and abilities, and to provide them with the right tools to address their needs and to be successful (Oxford dictionary, 2013b). Empowerment gives stakeholders the opportunity to meet their needs and to take control of their lives. Empowerment was described as the process through which power is shared 
between various individuals to ensure that all individuals possess some form of power that might mean that they can at least help themselves (see paragraph 2.2.1). Empowerment is not the only the transfer of knowledge and to make it one's own, but also the discovery of ventures, expertise and use of the knowledge that was gained.

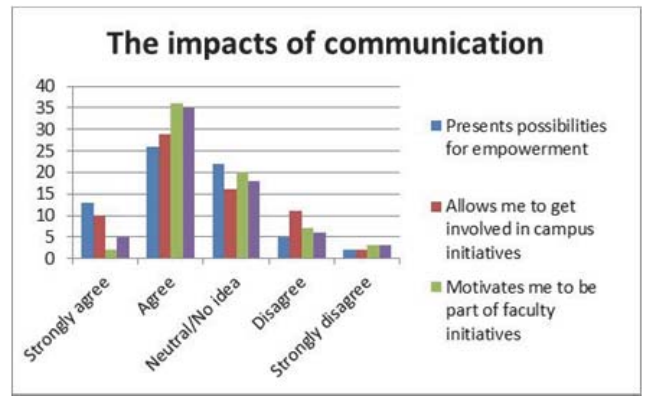

Figure 11: Communication impact summary

Figure 11, indicates if the communication within the Faculty is effective and motivates personnel to take part in empowerment opportunities. It was indicated by respondents that communication was perceived in a very positive manner. Personnel members are presented with information on different empowerment opportunities, this opportunities includes both Faculty and Campus initiatives. The different communication messages and the mediums that are used to portray different messages motivate them to be part of the Faculty and to get involved in new ventures.

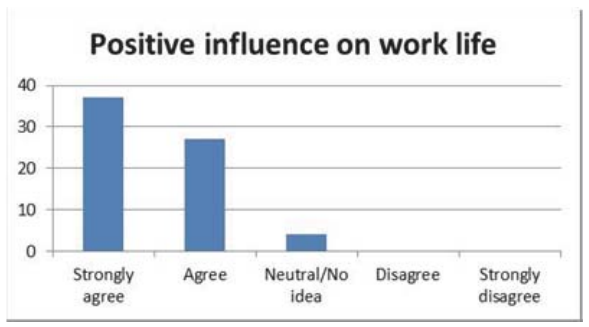

Figure 12: Impact of communication on work life

Figure 12 indicates that communication has a positive influence on the majority of personnel members. This can be because frequent communication on different topics and initiative goes out to personnel members. As indicated in 3.2 Communication is more than the mere transmission of information, but complete and effective dialogue is the product of multiperson interaction. No communication relationship can be built without dialogue (O'Sullivan et al.,, 1994:94; Waisbord, 2001:18; Roberts, 2010:9). No community can exist without dialogue between its members. It is important that there is interaction between the members of a community and that they share dialogue, experiences and opinions with one another (Rahim, 1994:120; O' Sullivan et al., 1994:49).

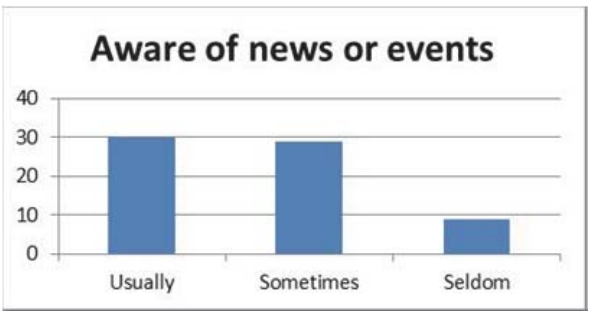

Figure 13: Awareness created by communication 
Figure 13 indicates that personnel members are aware of Faculty news, upcoming events and initiatives. The reason for this can be different communication mediums that are used to communicate with members. Research should however be done on the high amount of respondents that indicate that they are only sometimes or seldom aware of news or events. Research should focus on why the respondents are only sometimes or seldom aware of news, how can this be changed in order to decrease this number and move the usually column to a higher percentage.

\subsubsection{Cultural}

For any business or institution to survive in post-apartheid South Africa, they have to consider the cultural diversity of their stakeholders, in this research its employees.

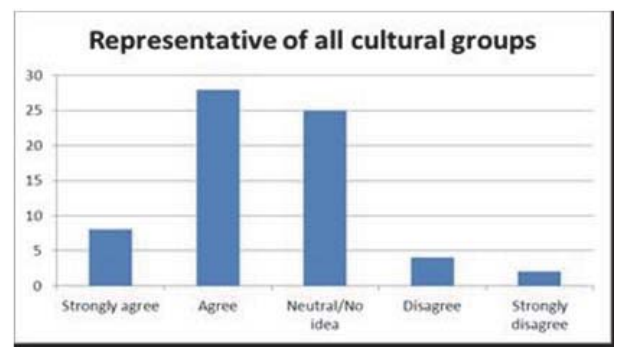

Figure 14: Communication representative of all cultural groups

As indicated in figure 14, current communication does consider cultural diversity, with only about $10 \%$ indicating that it is unrepresentative, about $40 \%$ indicating neutral, and about $50 \%$ indicating that current faculty communication is representative of cultural diversity. Even though current communication satisfies this need, it is important to be sensitive towards it and to keep considering it into the future. As shown in figure 15 there is a need for this type of consideration, and it should form part of all future communique, whenever it is applicable.

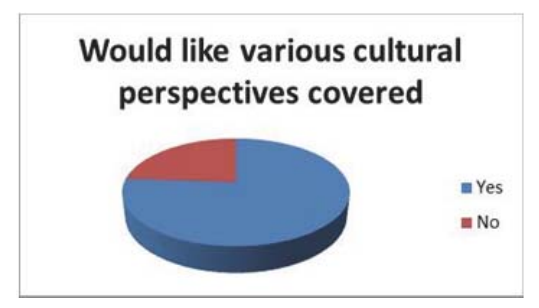

Figure 15: Importance of covering various cultural perspectives

South Africa is a very diverse country with numerous cultures. By covering different cultural perspectives all personnel members in the faculty will be represented and a better knowledge of different cultures, their way of thought and work ways will be described and better understood. Examples of covering different cultural perspectives can include information on Hanukkah, the Chinese New Year, Indian foods etc.

\subsubsection{General information gathered}

In an attempt to get away from the perception of communication only being a one-way occurrence, the research aimed to identify other roles that staff members of the faculty might like to have in communication. The question gave them four options, of which they could choose as many as they found applicable. Figure 16 shows the responses, and it is interesting to note that people are willing to get involved in all the stages of the process, from providing the newsworthy event, to preparing the story, right through to reading the end result. Getting more people involved will definitely increase the perceived importance of the communication in the faculty, thereby increasing its efficiency tenfold. 


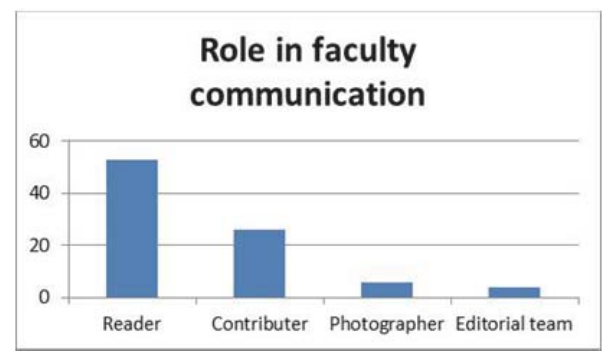

Figure 16: Role that participants would like to have in faculty communication

Active participation and dialogue create the opportunity for individuals to identify their needs by making use of indigenous knowledge, among other things (Taylor, 1993:56-57; Rahim, 1994:118, Roberts, 2007:513). Communities become a part of their own development and problem solving process. According to Roberts (2010:9), Bakahtin offers communication terms to offer better insight into the role of communication within education.

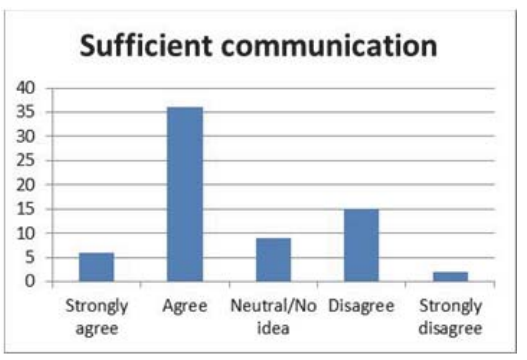

Figure 17: Sufficient communication within the faculty

Respondents indicated in figure 17 that there is sufficient communication within the Faculty. This is contrasting with the to the conclusion of figure 14 which states that respondents sometimes knows about events and news they as now in figure 17 they state that communication is sufficient. Communication cannot be sufficient if respondents are only sometimes informed or aware of news. Further research should therefore be done on figure 17 and 14 . The answer could be as simple as to change a communication medium, add a communication medium or change the times when communication mediums are being disseminated to ensure that personnel members receive and read the messages.

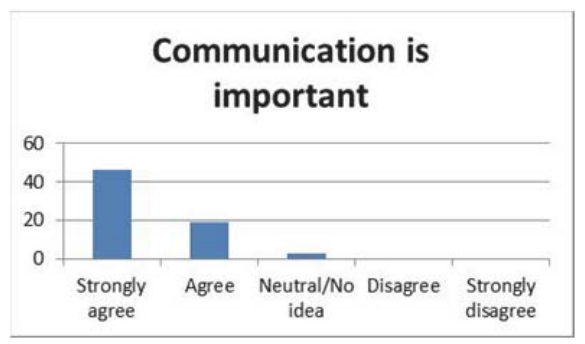

Figure 18: Importance of communication

Communication is a prominent human need, and is reflected in figure 18. Each individual has the need to send and receive messages, and to express his or her thoughts (Kamboura, 2008:2). Communication is a symbolic, interpretative, transactional, and conceptual process of sharing a specific message and transferring knowledge or information. It is a process of negotiation during which people from different cultures come into contact and where the meaning of the message is clearly understandable to all of those involved. It is the process of talking and asking questions in order to 
make new discoveries and understand different worlds (O'Sullivan et al., 1994:50; Waisbord, 2001:18; Lustig \& Koester, 2005:9-10; Roberts, 2010:6).

Communication is more than the mere transmission of information, but complete and effective dialogue is the product of multiperson interaction. No communication relationship can be built without dialogue (O'Sullivan et al., 1994:94; Waisbord, 2001:18; Roberts, 2010:9). No community can exist without dialogue between its members. It is important that there is interaction between the members of a community and that they share dialogue, experiences and opinions with one another (Rahim, 1994:120; O' Sullivan et al., 1994:49). Face-to-face communication and interaction provides people with the opportunity to express new ideas. Rahim (1994:20) argues that there can be no familiarity without dialogic communication. This implies that there has to be mutual communication with a view to bringing about a positive change of circumstances between all of the involved parties in order for development to take place. Without effective and efficient dialogue, the objectives of the organisation cannot be achieved (Mefalopulos, 2005:254).

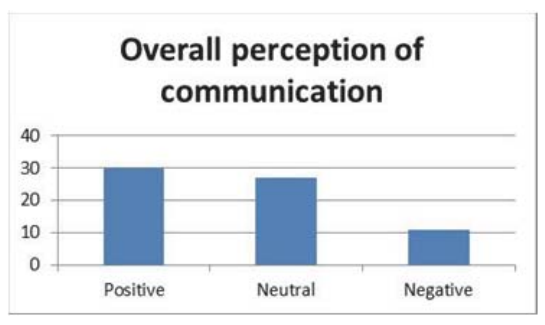

Figure 19: Overall perception of communication

It is important for personnel member to be positive towards communication and to experiences messages that is being sent to them in a positive manner, as is reflected to a large extent in figure 19. Kamboura (2008:3) argues that effective communication has a positive influence on the community and the operations of the organisation. When people are in a position to express their frustrations and talk about their problems, plans can be formulated collectively to solve these problems. Effective communication influences productivity and performance and leads to sustainable development (Servaes, 1995; Melkote \& Steeves, 2001:252).

\section{Conclusions and future research}

\subsection{Empowerment}

During this research it came to light that there are numerous development opportunities within the NWU Vaal campus as well as in the Faculty of Economic Sciences and IT. The empowerment options are endless and there is something for all the personnel within the faculty whether you are a support personnel member, a new lecturer or a lecturer that wants to focus more on research. The skills that can be obtained vary from basic computer skills, learning new computer software to how to write articles or other publications.

According to Maslow (2000) individuals are motivated to achieve certain standards and develop themselves and since individuals have motivation systems unrelated to rewards or unconscious desires (Maslow, 2000).

It was identified by stakeholders that even though they know about the different opportunities, they do not always have enough information on the development opportunity. This information includes information such as how will this empowerment improve me as a person, my work and my future. Personnel also want more information on what will be the chances of promotion. In the light of the above mentioned more information should be provided on the different research entities and development possibilities that are present in the Faculty. The information provided must answer most of the question that the personnel might have. By providing this information to personnel a clearer picture will be painted on why it is important not to stagnate but get regular training, and grow with the students of the community.

Personnel should also be motivated to share their training and empowerment opportunities. By doing this more personnel will be motivated to participate if they see that it is beneficial.

\subsection{Dialogue}

In development communication for social change one-way communication to persuade people is rejected and two-way 
communication between parties is encouraged (Melkote, 1991:270; Nair \& White, 1993:54; O'Sullivan et al., 1994:50; Malan, 1998:52; De Marchi et al., 2001). Frequent two-way communication and the participation of the community play an important role during development projects. More attention should be paid to the simplification of the communication structure and the identification and use of the correct communication mediums. Without communication no entrepreneurs or volunteers will know about the project, how to get involved or what is to be gained from their involvement. A full-scale awareness campaign is therefore needed.

Over the past couple of years the Faculty of Economic Sciences and IT developed various communication mediums. These mediums include traditional media as well as social media and other internet based mediums. The flow of information is important, since it is important to ensure that all members have the necessary information. Different communication mediums are used for different audience groups and different communication messages are developed to ensure the message is clear an understandable to that specific target audience. This research indicated that personnel, as an target audience, use email as a main means of communication. It also came to light that personnel would like an eFundi portal where all the Faculty news and announcements can be published on. The research indicated that the communication and usage of different mediums informs, encourages personnel to take part in different initiatives within the Faculty of Economic Sciences and IT. The frequent communication makes an positive influence on their work lives and creates a corporate culture to be proud of.

The need however developed for a full scale marketing and communication campaign. During this campaign messages should be be informative, interesting, entertaining and sometimes humorous (Melkote \& Steeves, 2001:252; Bakke \& Subedi, 2008:71, Melkote,1991:270; Saunders \& Goddard, 2002:2) and motivate to be part of the Faculty. There is a need to inform individuals about the different initiatives, research and development opportunities within the faculty. It is important to provide to personnel of the Faculty Economic Sciences and IT information on the different initiatives with in the faculty, and how they can get involved. This information will be provided by firstly taking the conventional route by communicating during the two monthly Faculty teas, through emails, and eFundi. A second route will be followed by providing the personnel with interactive marketing items to create curiosity and spark creativity.

It can therefore be concluded that there are enough empowerment opportunities within the Faculty of Economic Sciences and IT. The communication and information systems should just be alternated to address the need of personnel to obtain more information on different development opportunities.

\subsection{Future research}

Future research into development communication for social change and perceptions amongst staff members at tertiary education institutions should focus on:

1. The development of interesting messages to address the dynamic target group of academics.

2. Different communication and information campaigns within tertiary education institutions, to ensure that communication campaigns stays new and fresh. This research will ensure that the message is clear to target audiences like students, as technology changes rapidly.

\section{References}

Agunga, A.R. 1997. Developing the Third World: A communication approach. New York: Nova Science Publishers Agunga, R.A. 1996. Developing the Third World: a communication approach. Commack, New.York: Nova Science.

Agunga, R.A. 1999. Developing the world: a communication approach. New York: Nova Science Publishers.

Bakke, M. \& Subedi, M. 2008. Communication aspects in health care work in Nepal. Dhoulariri Journal of Sociology and Anthropology 2:65-100.

Cadiz, M.C.H. 2003. Communication for empowerment: the practice of participatory communication in development. (In Rola, A.C. \& Foranda, C.A.,eds. New frontiers in research for sustainable development. Los Bahaňos: Institute of Planning and Policy Studies, University of the Philippines, p 301-315).

Chitnis, K.S. 2005a. Communication for empowerment and participatory development. http://etd.ohiolink.edu/sendpdf.cgi/Chitnis\%20Ketan\%20S.pdf?ohiou1127144625 Date of access: 9 December 2011.

Chitnis, K.S. 2005b. The duality of development: recasting participatory communication for development using structuration theory. Investigation 230 desarrollo, (13):228-249.

Crabtree, R.B. 1998. Mutual empowerment in cross-cultural participatory development and service learning: lessons in communication and social justice from projects in El Salvador and Nicaragua. Journal of applied communication research, (1):182-209.

Fourie, L. \& Kloppers, E.M. 2009. Organizations as change-agents in HIV/AIDS programmes through participatory communication. Journal for community communication and information impact (14):89-104.

Haddad, T. \& Spivey, M. 1992. All or nothing: modernization, dependency and wage labour on a reserve in Canada. 
http://www2.brandonu.ca/library/cjns/12.2/haddad.pdf Date of access: 10 October 2011.

Langenhoven, H. 2001. The facilitating role of the Mmabatho ICDL Centre in the process of women empowerment: a development communication perspective. Potchefstroom: NWU. (Dissertation - MA).

Lustig, M.W \& Koester, J. 2006. Intercultural competence: interpersonal communication across cultures. 5th ed. Boston, New York and San Francisco. Pearson Education Inc.

Malan, C. 1998. Development communication as part of culture. Communicare, 17(1):49-87.

Mefalopulos, P. 2005. Communication for sustainable development: applications and challenges. (In Hemer, O. \& Tufte, T., eds. Media and global change: rethinking communication for development. Buenos Aires: CLACSO/ Nordicom).

Mefalopulos, P. \& Genna, L. 2004. Promoting sustainable development through strategic communication. (In Hamú, D., Auchincloss, E., Goldstein, W eds. Communicating protected areas. Cambridge: Commission on Education and Communication).

Melkote, S.R. 1991. Communication for development in the Third World: theory and practice. New Delhi: Sage Publications Ltd.

Melkote, S.R. \& Steeves, H.L. 2001. Communication for development in the third world: theory and practice for empowerment. New Dehli: Sage Publications Ltd.

Mies. M. 1973. Paulo Freire's method of education: conscientisation in Latin America. Economic and political weekly, 8(39):1764-1767.

Moemeka, A. A. 1999. Development communication and the new millennium: which way for Africa? http://www.eric.ed.gov/PDFS/ED437673.pdf Date of access: 27 October 2011.

Moemeka, A.A. 2002. Development communication in action: building and creating participation. Lanham: University Press of America.

Nair, K.S. \& White. S.A. 1994. Participatory message development: a conceptual framework. (In White, S.A., Nair, K.S. \& Ascroft, J., eds. Participatory communication: working for change and development. New Delhi: Sage Publications Ltd. p. 345-358).

Nulens, G. 2003. The digital divide and development communication theory. Communicatio, 29 (12):69-75.

O'Sullilvan, T., Hartley, J., Saunders, D., Montgomery, M. \& FISK, J. 1994. Key concepts in the communication and cultural studies. 2nd ed. London: Routledge.

Rahim, S.A. 1994. Participatory development communication as a dialogical process. (In White, A.S., Nair, K.S. \& Ascroft, J., eds. Participatory communication: working for change and development. New Delhi: Sage Publications Ltd).

Roberts, W. L. 2010. Dialogic interaction in online distance education: a Bakhtinian perspective. http://wroberts.weebly.com/uploads/3/6/5/2/3652409/dialogic_interaction.pdf Date of Access: 18 June 2013.

Schultz, H. 2003. Organisational behaviour: a contemporary South African perspective. Pretoria: van Schaik.

Servaes, J. 1995. Development communication for whom or what? Communicatio, 21(1): 39-49.

Servaes, J. 1995. Development communication in action: building understanding and strategic communication. Communicatio, 26(1): 84-89.

Servaes, J. 2000. Communication for development: Alive and kicking! Communicatio, 26(1):84-89.

Servaes, J. \& Malikhao, P. 2008. Development communication approaches in an international perspective. (In Servaes, J., eds. Communication for Development and Social Change. Los Angeles-London. New Delhi-Singapore: Sage Publications Ltd. 158$179 p$.

Taylor, P. 1993. The texts of Paulo Freire. London: Open University Press.

Waisbord, S. 2001. Family tree of theories, methodologies and strategies in development communication. Rockefeller Foundation. http://envirocom.files.wordpress.com/2008/03/theories-methodologies-strategies-in-development-communication.pdf .Date of access: 21 April 2011.

Yoon, CY. 2004. Participatory communication for development. http://www.southbound.com.my/communication/parcom.htm Date of access: 19 September 2011. 